\title{
Development of adaptive perturb and observe-fuzzy control maximum power point tracking for photovoltaic boost dc-dc converter
}

\begin{abstract}
This study presents an adaptive perturb and observe (P\&O)-fuzzy control maximum power point tracking (MPPT) for photovoltaic (PV) boost dc-dc converter. P\&O is known as a very simple MPPT algorithm and used widely. Fuzzy logic is also simple to be developed and provides fast response. The proposed technique combines both of their advantages. It should improve MPPT performance especially with existing of noise. For evaluation and comparison analysis, conventional $\mathrm{P} \& \mathrm{O}$ and fuzzy logic control algorithms have been developed too. All the algorithms were simulated in MATLAB-Simulink, respectively, together with PV module of Kyocera KD210GH-2PU connected to PV boost dc-dc converter. For hardware implementation, the proposed adaptive P\&O-fuzzy control MPPT was programmed in TMS320F28335 digital signal processing board. The other two conventional MPPT methods were also programmed for comparison purpose. Performance assessment covers overshoot, time response, maximum power ratio, oscillation and stability as described further in this study. From the results and analysis, the adaptive P\&O-fuzzy control MPPT shows the best performance with fast time response, less overshoot and more stable operation. It has high maximum power ratio as compared to the other two conventional MPPT algorithms especially with existing of noise in the system at low irradiance.
\end{abstract}

Keyword: DC-DC power convertors; Maximum power point tracking; Fuzzy control; Photovoltaic 